\title{
Maternal Healthcare Services and the Health Workers among the Migrant Slum Dwellers of Bangalore City, Karnataka, India
}

\author{
Suchismita Mishra ${ }^{1,2}$ and T. Rajendra Prasad ${ }^{1}$
}

'Department of Economics, Bangalore University, Bengaluru, India, ${ }^{2}$ Department of Biostatistics, National Institute of Mental Health and Neurosciences, Bengaluru, India

Correspondence: Suchismita Mishra (email: suchismita44@gmail.com)

\begin{abstract}
The health workers play a variety of roles which include provision of outreach, information, referral, advocacy and other support to promote health and help people meet their healthcare. The poor migrants usually settle in unauthorized slums or settlements. The migrant health is found in a disadvantageous position due to poor access to healthcare services. The present paper examines the maternal healthcare services provided by the peripheral health workers among the interstate migrants living in slums of Bangalore city. After conducting a pilot survey, five slums (migrant camps/non-notified slums) were identified based on the criteria of 1) interstate migration 2) year of migration $<7$ years 3 ) having more than 100 households. Mothers with a child below 2 years $(n=100)$ were interviewed with a pretested questionnaire. Qualitative data were collected from the mothers, key informants and healthcare workers through indepth interviews. The maternal healthcare services by the health workers are not able to reach the migrant population due to migrants' location of staying and many women went back to their native place for child delivery. The migrants who moved for delivery to their native place $(32.4 \%)$ accessed the services of the health workers better than the respondents who stayed in the Bangalore city (13.5\%). Similar situation was found for the visit of the heath workers for post-natal care. Some institutional lacuna like lack of space, toilets, water and also the shortage of staff etc. were pointed out by the health workers, which are required. The study warrants the need to understand the realities and healthcare needs of the migrant population. A better mechanism should be developed to improve the services of peripheral health workers in delivering primary healthcare services like maternal health care.
\end{abstract}

Keywords: internal migration; maternal healthcare; health workers; primary healthcare

\section{Introduction}

India's primary healthcare infrastructure includes a large cadre of healthcare providers, including various categories of frontline health workers (Kapil \& Choudhury, 2005). The health workers play a crucial role in delivering the primary healthcare services as they are the bridge between the health care providers and the community through developing a social support system. In India, health workers, viz, auxiliary nurse midwives, multipurpose 
health workers, health assistants, health visitors, and accredited social health activists (ASHA) etc. are the health workers working under the umbrella of the primary healthcare system. The health workers play a variety of roles which includes provision of outreach, information, referral to community resources, advocacy and other client support to promote health and help people meet their health needs.

The population in urban India is about 38 crores (Census of India, 2011). The level of urbanization is increased from $27.8 \%$ to $31.6 \%$ (2011 census). This clearly shows the burden on urban India which is expanding day by day and one of the major reasons is rural to urban migration. In contrast, the urban healthcare services and infrastructure is not found at a satisfactory level. Even the Eleventh Plan document acknowledges that there has been an increase in the number of urban poor, and that the civic authorities will have a daunting task in responding to their health and infrastructural needs (Planning commission, 2012). UNICEF (2015) also highlights the need of improvement of facilities for marginalized population living in the cities.

Migration is an unavoidable phenomenon particularly found in developing countries like India, as it is one of the important livelihood strategies of the poor. The migrants try to settle themselves in unauthorized or migratory camps due to their low economic condition. Maternal health in slums where migrants live are found in a disadvantageous position compare to the other non-slum urban areas as well as rural areas (Babu et. al. 2010; Kusuma et. al., 2010; Singh et. al., 2012; Swain \& Mishra, 2006). The poor access to maternal health is due to several factors, including inadequate health staffing and the exclusion of migrant pockets from primary healthcare services. This situation, along with the vulnerability and the livelihood insecurity of the migrant population, lead to poor access to healthcare and inequities exist in access, despite the high concentration of healthcare institutions in urban areas (Kusuma et. al., 2013). Few studies have opined that the health workers play a major role in increasing the utilization of maternal healthcare services in rural India mostly because of their door to door visit (Arends-Kuenning, 1997; Navaneetham \& Davara lingam, 2002). In this context, the people who have migrated to the urban area and settled in migrant camps or unorganized slums areas are usually less reachable by the health workers working in that particular region. This statement is supported by a study conducted by Kusuma, et. al., where it is stated that the migrant population living in the non-notified slums are still not accessible to the health services (Kusuma et. al., 2010).

Greater availability of health workers has been shown to be associated both with increased service utilization as well as health outcomes such as immunization coverage and child and maternal survival (Anand \& Barnighausen, 2004). In this regard, it is very important to understand the accessibility of health workers to this migrant population living in urban areas. This paper reports maternal healthcare services provided by peripheral health workers to the internal migrants living in slums of Bangalore, a South Indian City.

\section{Methodology}

Notified and non-notified slums were identified from the offices of municipalities and local bodies or development authorities. Households of eligible migrants were identified from various clusters in the city. 
Attempts were made to identify clusters, particularly from newer slums, de-notified slums and camps, where newcomers usually reside. Snow-balling technique was also used during the pilot survey for identifying this type of habitations. A mapping work/ interview with the influential person(s) of the slum area was carried out for collecting information on the number of household and age of the slum in each location (cluster) to meet the criteria of selection of study area. The field work was carried out during 2016-2017 as part of the post-doctoral research. The present study is a community-based study, undertaken in South Bangalore city of Karnataka. A pilot study was carried out across various slums/migrant settlements and identified five slums/migrant camps based on the criteria; i) interstate migration ii) migrated to the city within seven years. Only the slum locations which had more than 100 households considered as a cluster for inclusion in the study. Women who have conceived and delivered recently were included in this study.

After consulting with a statistician from National Institute of Mental Health and Neuro Sciences, Bangalore, India and by considering the $p$-value $=0.4$ and $d=0.1$, the sample size is 92.2. After adjusting with non-response rate, finally, the sample size is 100 .

The strength of the study is using mixed methods approach, with an advantage of using more qualitative data in understanding some of the hidden facts involved. The quantititive data were collected with the help of self-administered questionnaire which consists of questions to find out the level of utilization of healthcare services for delivery and antenatal care (ANC). The qualitative data were also collected by using a check-list on various issues, such as migration history, knowledge about the available health services, and details pertaining to the antenatal and postnatal care sought (including the number of visits and in which month they visited, health workers visited or not). Quantitative data were collected by interviewing 100 mothers with the criteria of having $<2$ years old child. Qualitative data were collected through indepth interviews with key informants, mothers of different categories and healthcare providers. All these in-depth interviews were conducted by following the guidelines of Pelto and Pelto (1978) and Lengeler et. al. (1991).

Data obtained in quantitative survey were entered into the computer through MS Excel, and the analyses were done using SPSS for Windows V.22.0. For analyzing qualitative data, qualitative data analysis software, ATLAS/ti for windows V.4.1 was used. All indepth interviews were held in the respondents' local language i.e. Telugu, Tamil and Hindi. They had been transcribed and translated into English.

\section{Result and Discussion}

The distribution of the respondents with regard to the availability of maternal healthcare services near to their slums, a majority of the respondents (64\%) said only private healthcare that is available. Followed by this, some respondents (12\%) said both government and private hospitals. A few respondents gave some mixed responses which includes government, private, Anganbadi (mother and childcare centers) and NGOs (Table 1).

The above data clearly shows that the availability of private healthcare services is better than the government healthcare centers and Anganbadi centers. However, as people are poor, it is very difficult for them to afford the private healthcare services. The 
Table 1. Distribution of Women by Availability of Healthcare Facility

\begin{tabular}{lc}
\hline Availability of Type of Healthcare Center & \\
\hline Private & $64(64 \%)$ \\
Government \& Private & $12(12 \%)$ \\
Private \& Anganbadi Center & $15(15 \%)$ \\
Government, Private \& Anganbadi Center & $7(7 \%)$ \\
Government, Private, nongovernemntal \& Anganbadi Center & $2(2 \%)$ \\
\hline Total & $\mathbf{1 0 0 ( 1 0 0 \% )}$ \\
\hline
\end{tabular}

migrant population are new to the area, so they are less aware about the exact location of the government health centers. In order to reduce the equity gap in maternal health services, marginalized women need more access to health services. Although, private health facilities are proliferating rapidly in urban areas, which are actually unaffordable for the slum poor people, in contrary public facilities are growing very slowly. Thus, it results in limited access to quality care for the poor (Adams, 2013). Therefore, maternal healthcare issues are not being tackled for a significant proportion of the urban population. Hence, there is an urgent demand to focus on the urban health, with the given pace of urbanization, the increasing number of urban slums with little access to healthcare facilities to cater to the essential living needs of urban population (Rao, 2000).

Table 2. Distribution of Women by the Visits of Health Workers during Pregnancy

\begin{tabular}{lcccc}
\hline Health Workers Visited & \multicolumn{3}{c}{ Stayed during Last Pregnancy } \\
\hline During delivery time & City & $\begin{array}{c}\text { Native } \\
\text { Place }\end{array}$ & $\begin{array}{c}\text { Both } \\
\text { Places }\end{array}$ & Total \\
\hline $\begin{array}{l}\text { Yes, the health worker } \\
\text { visited }\end{array}$ & $5(13.5 \%)$ & $12(32.4 \%)$ & $20(54.1 \%)$ & $37(100.0 \%)$ \\
$\begin{array}{l}\text { Visited within 1-3 months of } \\
\text { pregnancy }\end{array}$ & $1(9.1 \%)$ & $6(54.6 \%)$ & $4(36.3 \%)$ & $11(29.7 \%)$ \\
$\begin{array}{l}\text { Visited within 4-6 months of } \\
\text { pregnancy }\end{array}$ & $4(21.0 \%)$ & $5(26.3 \%)$ & $10(52.6 \%)$ & $19(51.3 \%)$ \\
$\begin{array}{l}\text { Visited within 7 to 9 months } \\
\text { of pregnancy }\end{array}$ & $0(0.00 \%)$ & $1(14.2 \%)$ & $06(85.7 \%)$ & $07(19.00 \%)$ \\
1-3 times visited & $3(13.0)$ & $4(17.3 \%)$ & $16(69.5 \%)$ & $23(62.2 \%)$ \\
$4-6$ times visited & $2(18.2 \%)$ & $6(54.6 \%)$ & $3(27.2 \%)$ & $11(29.73 \%)$ \\
Visited more than 6 times & $0(0.00 \%)$ & $2(66.7 \%)$ & $1(33.3 \%)$ & $3(08.11 \%)$ \\
\hline
\end{tabular}


Table 3. Distribution of Women by Visits of the Health Workers after Delivery

\begin{tabular}{llll}
\hline \multirow{2}{*}{ Health Worker Visited } & \multicolumn{2}{c}{ Years of Migration } & \multirow{2}{*}{ Total } \\
\cline { 2 - 3 } & \multicolumn{2}{c}{ Less than 3 years } & \multicolumn{1}{c}{ to 7 years } \\
\hline Visited & $26(43.3 \%)$ & $9(22.5 \%)$ & $35(35 \%)$ \\
Not visited & $34(56.7 \%)$ & $31(77.5 \%)$ & $65(65 \%)$ \\
\hline
\end{tabular}

Table 2 presents whether the health workers visited them during pregnancy or not and the place they were staying during that time. Out of 100 respondents, only a considerable number of respondents $(37 \%)$ said that the health workers visited them and among them, a majority of the respondents $(54.1 \%)$ stayed in both the places (their native place and the current habitational area) during that time. Followed by this, some respondents $(21.4 \%)$ stayed in their native place. Only a considerable number of respondents (13.5\%) said they stayed in the city only. Among the 37 respondents who said the health worker visited them during their pregnancy period, a majority of the respondents $(51.3 \%)$ revealed that they visited them during their 4-6 months of pregnancy and followed by this some respondents who said $(29.7 \%)$ they visited them during their 1-3 months of pregnancy. Some respondents $(19.0 \%)$ also stated that they visited during their 7-9 months of pregnancy.

It is clearly visible from Table 3 that only some of the respondents (35\%) said that the health workers visited them after the delivery for the post-natal care. Interestingly, the more cases are found among the recent migrants (less than 3 years of migration) proveing that the recent migrants like to move to their native pace more, compared to the earlier migrants (more than four years to - seven years of

\section{Table 4. Distribution of Women by the Details of Visits of Health Worker after Delivery}

\begin{tabular}{llll}
\hline Health Workers' Visit & \multicolumn{3}{c}{ Stay during Delivery } \\
\hline Pregnancy Happened & Native (n=67\%) & City (n=33\%) & $\begin{array}{c}\text { Total } \\
(100)\end{array}$ \\
\hline Health workers visited & $33(49.2 \%)$ & $2(6.0 \%)$ & 35 \\
Visited within 7 days of delivery & $14(20.9 \%)$ & $0(0 \%)$ & $14(14 \%)$ \\
Visited after 7-15 days of delivery & $15(22.4 \%)$ & $0(0 \%)$ & $15(15 \%)$ \\
Visited after 15-30 days of delivery & $03(4.4 \%)$ & $02(6.0 \%)$ & $05(5 \%)$ \\
Visited more than 30 days of delivery & $01(1.5 \%)$ & $0(0 \%)$ & $01(1 \%)$ \\
Visited once & $00(0 \%)$ & $01(3.0 \%)$ & $01(1 \%)$ \\
Visited two to four times & $30(44.8 \%)$ & $01(3.0 \%)$ & $31(31 \%)$ \\
Visited five to six times & $03(4.4 \%)$ & $00(0 \%)$ & $03(3 \%)$ \\
\hline
\end{tabular}


migration) for delivery. The distribution of the respondents in terms of whether the health worker visited after delivery or not is presented in Table 4. Out of 67 respondents who stayed in their native place, a majority of the respondents $(49.2 \%)$ were visited by health workers. Out of 33 respondents, only a few respondents $(6.0 \%)$ who stayed in the city during their delivery said that the health workers visited them after their delivery. Out of 100 respondents, only some of the respondents $(15 \%)$ agreed that the health workers visited them within 7-15 days of their delivery. A considerable number of respondents $(31 \%)$ revealed that the health workers visited two to four times during their postnatal period. Most maternal deaths can be prevented if women have access to basic medical care during pregnancy, childbirth and postpartum period (WHO, 1994). In India, these services are provided through a network of healthcare centers in outpatient clinics, as well as through home visits by health workers (Government of India, 1992). However, utilization of these services by the target population continues to be poor (Kumar, 1995). This could happen due to the lack of awareness, availability or accessibility to these services.

However, it is evident from Table 2, 3 and 4 that the respondents who migrated to their native place during delivery are found in a better position compared to the respondents who stayed in the city in both prenatal and postnatal periods. This means that the prenatal, as well as the postnatal visits of health workers, occurred more in native place (rural area) compared to the urban slums. Even, the qualitative data revealed that the health workers are more helpful in their native (rural) place. Home visiting by female $\mathrm{CHWs}$ during the antenatal and postnatal periods is likely to be an important way to improve the demand for and use of maternal and child health services in fragile and conflict-affected countries such as Afghanistan (Burki, 2016; Pfaffmann et. al., 2017; Black et. al., 2017; Gopalan, 2017). Lack of proper visiting of the health workers to the study area population helps to lower the utilization of healthcare services which is proved from other studies. A clear dose response of increasing antenatal and prenatal care service use with increasing intensity of health workers home visiting (Lassi, 2018; Friberg, 2010; Karim, 2013).

The above incidence of both prenatal and postnatal delivery services are found better among the respondents who moved to their native place for the delivery compared to the respondents who stayed in the city. This finding is supported by the study conducted by USAID (2016), where it is noted that the healthcare services are found better in rural areas due to National Rural Health Mission and unlike to the urban area, where no attempts are made to provide the health care services to the areas that are having geographically delineated population.

However, the qualitative data from the ASHA workers, Anganbadi and other health workers working in the areas revealed that they provide various services to the slum population which includes giving supplementary food, vaccination, check the blood pressure, height and weight measurements of the pregnant women, provide medicines for minor illnesses to the mother as well as their new born. In case of requirement, they call the ambulance and sometimes accompany the patients in case of emergency. Few mothers said that they availed the services of the health workers and they are satisfied with the services. Even, few mothers got food supplements which include rice, jaggery, wheat, etc. which is available free of cost. However, many migrants have not 
availed the services and the reasons are that they do not know the location, they cannot go alone and they feel difficulty to communicate properly with the health workers. Hence, the accessibility of the health services provide by the health workers are found low. Similar findings were obtained by Mishra et. al. (2015) where they mentioned that unawareness about the physical location of the government health centers is one of the major barriers to access government health centers by the migrants.

However, the qualitative dada collected from the health workers reveals that the health workers uses various types of IEC/health education activities to the slum dwellers for improvement in antenatal, pregnancy and postnatal health services such as distribute pamphlets and images in local language; do make an announcement with the help of local mosque; visit door to door on certain days and inform people or else whenever the people visit the healthcare centers they inform. When enquired about the existence of any specific program for the migrant population, they accepted that there is no migrant specific program available right now. Hence, the study population needs migration specific health education program. In this regard, Gardner and Blackburn (1996) pointed out that there is an increasing concern about migrant women having less access to reproductive health information and services than non-migrants. It was reported that there is an increasing concern about migrant women having less access to reproductive health information and services than non-migrants.

A health worker in the Anganbadi healthcare center aged 49 years with work experience of 24 years said, "Not much, sometimes pamphlets are distributed for how to take care during pregnancy, after delivery and before delivery in local languages with pictures. When they visit, here I give them, otherwise when I visit their houses I inform them. I give information about contraceptives like IUD, OD, etc.

The healthcare providers said that they faced many difficulties while delivering the services especially to the slum dwellers and migrants. Even though communicating with the migrants is not at all an issue for them as the anganwadis are mostly in the schools. Therefore, in case of language problem, the school teachers help. The main problem is that, as the migrants move to their native place during the pregnancy time, it is difficult for them to trace and maintain their health records. Thus, the migrants miss many antenatal care visits. The other problems pointed out by the health workers are lack of space, basic infrastructure services like provision of drinking water, toilet facility, and shortage of staff members in the health centers.

One of the junior health assistants in a health facility said "I can speak in Hindi to some extent but they are not ready to listen----- what to do. They are not available also. They go to their native in between and coming here after a long gap or shifting to some other place. We cannot keep a record of them also."

Lack of sufficient manpower and basic infrastructure are one of the drawbacks of less utilization of healthcare services. In this regard, it was found that redesigning and reorganizing existing space in the health facility helped to make better use of the existing infrastructure and alleviate patient's bottlenecks, presenting a possible approach in some circumstances (Namazzi et. al., 2015). Due to the lack number of staff, the work pressure on them is more and this definitely effects on delivering the services effectively. Similar findings are found in the USAID report where it was 
mentioned that depleted workforces lead to a higher demand on existing workers, with the subsequent high workloads impacting the quality of care (USAID, 2016).

\section{Conclusion}

The present study concludes that the availability of private healthcare centers is more for the poor migrant communities they cannot afford. The health workers visiting to the study area is found to be very dissatisfactory. The utilization of prenatal and postnatal healthcare services among the study population is also not up to the level of satisfaction. The respondents who moved to their native place for delivery are found at a better position, compared to the respondents who stayed in the city. The recent migrants availed more maternal healthcare services than the earlier migrants. The health workers face some difficulties while providing their services due to mobility of the migrant population to their native place, lack of basic infrastructure services and lack of staff, etc. Hence, this study emphasizes the need to improve the existing government health workers services in the study area with a migration sensitive approach to make the migrants comfortable in the urban area. Therefore, the accessibility, affordability and utilization of maternal healthcare services can be achieved. The door to door visits for prenatal and post-natal maternal healthcare services performed by the health workers should be strengthened to bridge the gap between the study population and the health workers. Along with this, the healthcare centers' infrastructure should be improved for the target population as well as the healthcare provider to increase the utilization level of the healthcare services.

\section{Acknowledgement}

The present study is a part of postdoctoral research conducted out by the first author, which is funded by the Indian Council of Social Science Research, New Delhi.

\section{References}

Anand, S. and Bärnighausen, T. 2004. Human Resources and Health Outcomes: Crosscountry Econometric Study. Lancet, 364, 1603-09.

Arends-Kuenning, M. 1997. The equity and efficiency of door step delivery of contraceptives in Bangladesh. Research division working paper no. 101. New York: Population Council.

Babu, B.V., Swain, B.K., Mishra, S. and Kar, S.K. 2010. Primary Healthcare Services among a Migrant Indigenous Population Living in an Eastern Indian City. Journal of Immigrant and Minority Health, 12, 53-59.

Black, R.E., Taylor, C.E., Arole, S., Bang, A., Bhutta, Z.A. et al. 2017. Comprehensive review of the evidence regarding the effectiveness of community-based primary health care in improving maternal, neonatal and child health: 8. Summary and recommendations of the expert panel. J Glob Health, 7(1), 010908.

Burki, T. 2016. Conflict in Afghanistan takes an increasing toll on civilians. Lancet, 388 (10040), 117-8

Friberg, I.K., Bhutta, Z.A., Darmstadt, G.L., et al. 2010. Comparing modelled predictions of neonatal mortality impacts using List with observed results of community-based intervention trials in South Asia. Int J Epidemiol, 39(Suppl 1), i11-20. 
Gardner, R. and Blackburn, R. 1996. People Who Move: New Reproductive Health Focus. Population Reports, XXIV (3).

Gopalan, S.S., Das, A. and Howard, N. 2017. Maternal and neonatal service usage and determinants in fragile and conflict-affected situations: a systematic review of Asia and the middle-east. BMC Women's Health, 17(1), 20.

Government of India, 1992. National Child Survival and Safe Motherhood Programme: Plan to implement MCH Services. Ministry of Health and Family Welfare, Government of India: New Delhi.

Kapil, U. and Choudhury, P. 2005. National Rural Health Mission (NRHM): Will It Make a Difference? Indian Pediatrics, 42, 783.

Karim, A.M., Admassu, K. and Schellenberg, J. 2013. Effect of Ethiopia's health extension program on maternal and newborn health care practices in 101 rural districts: A doseresponse study. PLoS One, 8(6), e65160.

Kumar, R, Singh, M.M., Kaur, A., Kaur, M. 1995. Reproductive health behaviour of rural women. J Indian Med Assoc, 93, 12931.

Kusuma, Y.S., Kumari, R. and Kaushal, S. 2013. Migration and Access to Maternal Healthcare: Determinants of Adequate Antenatal Care and Institutional Delivery among Socio-Economically Disadvantaged Migrants in Delhi, India. Tropical Medicine and International Health, 18(10), 1202-1210.

Kusuma, Y.S., Kumari, R., Chandrakant, S.P. and Gupta, SK. 2010. Migration and Immunization: Determinants of Childhood Immunization Uptake among Socioeconomically Disadvantaged Migrants in Delhi, India. Tropical Medicine and International Health. 15(11), 1326-1332.
Kusuma, Y.S., Kumari. R, Pandav. C.S. and Gupta, S.K. 2010. Migration and immunization: determinants of childhood immunization uptake among socioeconomically disadvantaged migrants in Delhi, India. Tropical Medicine \& International Health, 1:15 (11), 1326 -32. Lassi, Z.S. and Bhutta, Z.A. 2015. Communitybased intervention packages for reducing maternal and neonatal morbidity and mortality and improving neonatal outcomes. Cochrane Database Syst Rev, 3:CD007754.

Mishra, S. Yadlapalli, K. and Babu, B.V. 2015. Migration and health-care access: Barriers to access government health services by migrant tribal community living in an eastern Indian city. International journal of medical science and public health, 4(1), 181-188.

Namazzi, G., Waiswa, P., Nakakeeto, M., Nakibuuka, V. K., Namutamba, S., Najjemba, M., and Peterson, S. 2015. Strengthening Health Facilities for Maternal and Newborn Care: Experiences from Rural Eastern Uganda. Global health action, 8.

Navaneetham, K. and Dramalingam, A. 2002. Utilization of maternal healthcare services in Southern India. Social Science \& Medicine, 55(10):1849-1869.

Pandve, H.T. and Pandve, T.K. 2013. Primary Healthcare System in India: Evolution and Challenges. Int J Health Syst Disaster Manage, 1(3), 125-128.

Pfaffmann, Z. J., Rasanathan, K. and Hipgrave D.2017. Community healthsystems: allowing community health workers to emerge from the shadows. Lancet Glob Health, 5(9), e866-e7.

Planning Commission, Government of India, 2008. Eleventh Five Year Plan: 2007- 
12: Social Sector (Volume II). Oxford University Press, New Delhi.

Rao, S., Joshi, S.B., Kelkar, R.S. 2000. Changes in nutritional status and morbidity over time among pre-school children from slums in Pune, India. Indian J Pediatr, 37(10),1060-71.

Singh, P.K., Rai, R.K. and Singh, L. 2012. Examining the Effect of Household Wealth and Migration Status on Safe Delivery Care in Urban India, 1992-2006. PLoS One, 7: e44901.

Swain BK, Mishra S. 2006. Immunization Coverage among Migrant Tribal Children in Slums of Orissa. Indian Pediatr. 43(11), $1011 \square 1013$.

UNICEF, Women UN, 2015. Addressing Inequalities: Synthesis Report of Global Public Consultation. Global Thematic Consultation on the Post - 2015 Development Agenda, TheWorldWeWant2015. 2013 Jun.

USAID, 2016. The Health Communication Capacity Collaborative (HC3). (2016) Factors Impacting the Effectiveness of Health Care Worker Behavior Change: A Literature Review. Baltimore: Johns Hopkins Center for Communication Programs.

Usmani, G. and Ahmad, N. 2018. Health Status in India: A Study of Urban Slum and Non-slum Population. Nurs Res Pract, 2(1), 9-14.

Worl Health Organization, 1994. Mother-baby package: Implementing safe motherhood in countries. Geneva. 